\title{
Cânone e Desejo: Sete Abordagens para Palestras/Performances Histório-coreográficas ${ }^{1}$
}

\section{Resumo}

Ao exibir a apreciação do cânone e do desejo como partes do processo artístico, bem como do acadêmico, palestras/performances podem ser vistas como modelos para "pesquisa de arte" em termos de complexidade de conteúdos e metodologias, táticas e estratégias durante os atos de pesquisa, adaptação física e apresentação da dança.

Palavras-chave: Dança, Teoria, Convenção

Proponho sete abordagens que conectam os modos de atenção das palestras/performances aos modos de teoria e historiografia da dança e, como historiadora e re-construtora, incluo a questão das histório-coreografias. Parto da noção de que estes modos estiveram e estão continuamente presentes - em resumo, como subtextos, pré-condições e qualificações, sempre que a comunidade da dança usou e transformou cânones e instituições e baseou-se em desejo e paixão, a fim de materializar a consciência do conhecimento e da habilidade em dança - respondendo a códigos e convenções e sempre crítica e criativamente ultrapassando-os.

\section{UM - Conhecimento da Dança / Conhecimento na Dança}

A construção do conhecimento da dança ocorreu quando os estudiosos da dança começaram a se envolver sistematicamente com dança - dentro e fora de instituições.

\footnotetext{
${ }^{1}$ Nota da tradutora: Título do artigo no original, em inglês: Canon and Desire - Seven Approaches to HistorioChoreographical Lecture/Performances - optamos por traduzir a palavra lecture como palestra e manter o termo em inglês performance em todo o artigo.

2 Dançarina, coreógrafa, historiadora, professora de estudos da dança, Dra. Claudia Jeschke formou-se profissionalmente em várias formas da dança. Estudou Teatro (Theaterwissenschaft) na Universidade de Munique, sendo que sua tese de doutorado é sobre a história dos sistemas de notação da dança. A experiência acadêmica e prática de Jeschke a levou para reviver a história da dança tanto no palco como na escrita acadêmica. Como professora convidada, ministrou aulas na Europa, EUA, Canadá e Ásia, e é membro efetivo do corpo docente das universidades de Munique, Leipzig, Colônia e, desde 2004, Salzburgo. Além disso, encabeça o Derra de Moroda Dance Archives, uma das mais importantes coleções da dança na Europa.
} 
Sua abordagem nas últimas duas ou três décadas alterou hierarquias tradicionais de história, teoria e prática, noções de certo e errado, do que é e do que não é aceito como conhecimento, e isso deu início ao repensar dessas oposições de modo orientado ao processo e rizomático ao invés de linear e ideológico.

Gostaria de sugerir a leitura do formato de palestra/performance como saída adequada e mediação das realizações rizomáticas em "dança enquanto prática"3 nas últimas duas décadas. Simplificando: o formato de palestra/performance suporta formas atuais de se envolver com o conhecimento da dança.

Performance e performatividade podem ser entendidas como técnicas culturais que questionam a supremacia da textualidade e da leitura através das estruturas móveis do in actu, in motu. E vice-versa: a palestra/performance, combinando o erudito e o discursivo com o artístico e aistético, mudou os modos tradicionais de performar, introduzindo uma dimensão crítica e auto-reflexiva:

A palestra e a performance apresentam-se, em seus modos de comunicação, como coreografias e cenografias de fala e de comunicação: um espaço se abre no qual algo se torna evidente precisamente através de camadas de falas que demonstram e de demonstrações que falam. ${ }^{4}$

\section{DOIS - Evidência / Des-cobertas}

Mas o que é esse algo que se torna evidente na palestra/performance?

Evidência, como termo fenomenológico, "não lida com dados fornecidos, mas com potencialidades" . Nesse sentido, as palestras/performances visam, principalmente, o surgimento de uma área que se encontra entre evento e percepção. E como qualquer performance, elas o fazem de várias formas - no nível de produção e recepção, ou seja, através dos performers e do público, que constantemente trocam de papéis: auto-apresentação e auto-reflexão ocorrem em níveis diferentes, no nível da narração

\footnotetext{
${ }^{3} \mathrm{O}$ termo 'dança como prática' disponibiliza diferentes possibilidades de lidar com o conhecimento de dança médico e terapêutico, pedagógico e didático, artístico e estético. Assim, o termo é abrangente o suficiente para capturar a complexidades atual, assim como a tradicional, e a diversidade da dança. Cheryldee Huddlestone usa o termo 'dança-como-prática' em um contexto diferente em sua tese ainda não publicada The Photograph is ReCalled as the Dancer's Body Re-Turns: The Performative Memory of Vaslav Nijinsky in L'Après-Midi d'un Faune. The University of Georgia, Athens, Georgia 2010. Agradeço a Cheryldee Huddlestone por gentilmente permitir a citação.

4 "Lecture und Performance erweisen sich beide, in ihrer Mit-Teilung, als Choreografien und Szenografien des Sagens und Zeigens: Er eröffnet sich ein Raum, indem sich etwas zeigt, das nur in dieser Überlagerung des zeigenden Sagens und des sprechenden Zeichens evident wird." Brandstetter, Gabriele: Tanzen Zeigen. Lecture performance im Tanz seit den 1990er Jahren. In: Bischof, Margrit; Rosiny, Claudia (eds.): Konzepte der Tanzkultur. Wissen und Wege der Tanzforschung. Bielefeld: transcript 2010, p. 45-61, p. 50.

${ }^{5}$ Françoise Dastur, citado em Huddlestone, Performative Memory, p. 19.
} 
e no nível da demonstração, bem como no nível de suas respectivas recepções. 0 cruzamento entre falar e demonstrar aponta para a importância da frequentemente inquietante "experiência de algo" que ocorre no espaço liminar entre julgamento e experiência sensorial que está além do julgamento.

O que é dito em palestras/performances não segue nenhuma norma retórica obrigatória e varia do comentário pessoal para a palestra acadêmica. A palavra - sua transmissão de informações e seu efeito - torna-se importante como um meio que permite ao dançarino detalhar as ações da dança e sublinhar a competência dele ou dela. A palestra pode ser entendida como a apresentação verbal de um processo de leitura que ocorreu antes da performance; introduzindo um termo literário nas artes performativas, poderia-se falar de uma estratégia ensaística. O "ensaio" geralmente comenta sobre os mais diversos conceitos e fenômenos da arte moderna; ao integrar diferentes materiais culturais, ele tenta determinar e fazer falar as condições e os limites de nosso pensamento no meio genuíno da literatura. Esta estratégia de questionamento como uma forma ensaística de pensamento em camadas e sua demonstração também podem ser encontrados na forma de palestra/performance.

O formato da palestra/performance foi introduzido em um contexto teatral em 1998, quando Xavier Le Roy apresentou Produto das circunstâncias. Outro protagonista deste formato é Jérôme Bel, que convidou artistas da dança para ilustrar as fricções entre suas biografias profissionais e suas experiências pessoais. Le Roy, bem como Bel (e há muitos outros) tem mostrado - no palco - memórias/histórias que, tradicionalmente, são disfarçadas em contextos teatrais ou espetaculares.

Des-cobertas, re-cuperações, o des-vendar de histórias - não o inventar - formam a motivação e conteúdo das palestras/performances: histórias que estão presentes nas biografias pessoais dos dançarinos, bem como nas histórias da dança.

Assim como as biografias pessoais, as histórias da dança - como biografias culturais - fornecem temas de herança que estão sempre ativos (assim como ocultos) quando dançarinos dançam. A história da dança pode ser concebida como um aspecto atraente e influente da memória que é - como a biografia pessoal - sempre existente na performance atual. Como a biografia, a história da dança não depende do fato de os dançarinos quererem ou não que ela afete, manipule ou controle a sua dança; ao contrário da biografia, a história da dança ainda não recebeu crédito (suficiente) para desempenhar um papel vital, crítico e/ou criativo na dança. 


\section{TRÊS - Técnicas corporais e Histórias do corpo}

Qualquer técnica de dança é [...], ao mesmo tempo uma memória corporal, um tipo de armazenamento, e uma forma de acesso ao corpo, uma atividade. Isto também implica ser um tipo de conhecimento específico para o corpo que dança, uma vez que precisa se relacionar com o espaço e o tempo, e também com outros dançarinos no espaço. O corpo que dança se transforma em um arquivo de experiências codificadas em movimentos e passos. Este conhecimento é transmitido por via oral sob a forma de instruções e fisicamente através da imitação, ele é também registrado por escrito, através de manuais, bem como pictoricamente na forma de fotografias, vídeos ou diagramas. Consequentemente, é uma prática que faz uso de diversos meios e uma prática que, como tal, não pode ser representada ou capturada textualmente. Seu conhecimento, além disso, é o conhecimento de situações culturais e os discursos em que se desenvolveu. O corpo é uma formação histórica contemporânea; na dança é possível acompanhar os vestígios da sua história, suas narrativas e as emoções associadas. ${ }^{6}$

Parece significativo neste contexto que Gerald Siegmund atribua "o potencial de resistência, de fricção com a falta de memória e, consequentemente, de corporalidade" à dança como uma forma de memória do corpo e para o corpo como um local de memória. Ele continua:

Em termos de estética, a memória da dança não está interessada em uma formação arquivística de identidade; em lugar disso, procede da ideia da divisão do sujeito, em cujas lacunas procura rastrear o que é heterogêneo. ${ }^{8}$

Como é possível obter acesso a um entendimento heterogêneo do conhecimento histórico baseado em apropriação física? Como esse conhecimento se traduz em leituras e apresentações teatrais críticas, provocativas e às vezes subversivas? Fornecendo um lugar para pesquisa incomum, desconhecido - novo -, pode o formato de palestra/performance ser aplicado a um campo mais vasto de produções teatrais,

\footnotetext{
6 "Jede Tanztechnik ist [...] sowohl ein Körpergedächtnis, eine Art Speicher, als auch der Zugang zu ihm, eine Aktivität. Das heißt aber auch, dass sie ein bestimmtes Wissens des tanzenden Körpers ist, wie er sich in Raum und Zeit sowie zu anderen Tänzern im Raum verhalten muss. Der tanzende Körper wird zum Archiv von Erfahrungen, die in Bewegungen und Schritten kodiert sind. Dieses Wissen wird im Unterricht zwischen Lehrer und Schüler sowohl mündlich in Form von Anweisungen weitergegeben als auch körperlich durch Nachahmung erfahren, es ist schriftlich in Handbüchern oder bildlich in Form von Fotografien, Videos oder Diagrammen festgehalten. Es ist mithin eine Praxis, die sich unterschiedlicher Medien bedient und die nie als solche abbildbar oder schriftlich fixierbar ist. Dieses Wissen ist darüber hinaus auch ein Wissen von der kulturellen Situation und ihren Diskursen, in der es sich herausgebildet hat. Der Körper ist eine aktualisierte historische Formation, in die man sich tanzend hinein begibt, um sich auf die Spuren seiner Geschichte, seiner Geschichten und der damit verbundenen Emotionen zu begeben." Siegmund, Gerald: Archive der Erfahrung, Archive des Fremden. In: Bischof, Rosiny (eds.), Konzepte der Tanzkultur, p. 171-180, p. $172 f$.

7 "[...] das Potential des Widerstands, der Reibung an der Gedächtnis- und damit Körperlosigkeit [...]". Siegmund, Archive der Erfahrung, p. 175.

8 "Nicht um archivarische Identitätsstiftung geht es dem Gedächtnis des Tanzes in ästhetischer Hinsicht, es geht eher von einer Spaltung des Subjekts aus, in dessen Zwischenräume es sich auf Spurensuche nach Heterogenem begibt." Siegmund, Archive der Erfahrung, p. 175.
} 
produções que vão além da "biografia enquanto história" e integram a "história da dança enquanto história" nas "histório-coreografias"? Vou embarcar em uma exploração que eu gostaria de identificar como discursos performáticos de histório-coreografias ou "história da dança enquanto prática".

\section{QUATRO - Experimentando com a História da Dança enquanto Prática}

No palco, há dançarinos e historiadores - envolvidos em uma conversa falada e corporificada. Eles compartilham um processo em que, ao contrário do formato da maioria das palestras/performances biográficas, um tipo de conhecimento está em jogo, o qual, retomando a terminologia de Gerald Siegmund, busca "rastrear" o que é "heterogêneo" nas "lacunas" da memória do corpo, uma memória considerada subversiva. Isso se desdobra dialogicamente e sob uma perspectiva compartilhada sobre a história da dança, que não gira em torno da perspectiva subjetiva de um único artista. A estratégia deste tipo de rastreio segue inicialmente os chamados momentos significativos da história da dança, conforme tenho aprendido - como historiadora - nos meus projetos colaborativos com inúmeras pessoas da dança.

Usando momentos significativos da história da dança, o trabalho rastreia os programas de conhecimento que existem nas mentes e corpos de bailarinos e estudiosos. O que esta abordagem conjunta tenta fazer é o seguinte: trocar o "estudo da invenção" pela "consciência da memória". Lidando com a performance a partir deste ponto de vista, tentamos identificar fontes históricas como exemplos de práticas, ou seja, tratamos as imagens, anotações, descrições, partituras musicais como vestígios ou fragmentos do vocabulário do movimento, de coreografia, de performance. Estas fontes são utilizadas para dar suporte à memória do bailarino, bem como à mente discursiva do estudioso - e vice-versa. Nós exploramos o campo e a atividade da consciência corporificada, bem como a corporificação consciente. Ao fazer isso, nós conectamos recordações de memórias como eles existem como arquivos, como arquivos do corpo e como arquivos de movimento com a experiência de performances atuais. Nós nos referimos a um termo que a teórica da performance Peggy Phelan introduziu quando definimos esta experiência como uma "negociação com um real inverificável"'

A historiadora da dança Cheryldee Huddlestone reformulou esta expressão para o uso da "história da dança enquanto prática" como "negociação com um irreal

\footnotetext{
${ }^{9}$ Phelan, Peggy: Unmarked. The Politics of Performance. London, New York: Routledge 1993, p. 1.
} 
verificável"10. O cenário das histório-coreografias amplifica estas negociações ao lidar com "momentos significativos da história da dança", por explorar "encontros de performance" e acolher vestígios, descontinuidade e fragmentação.

\section{CINCO - Momentos Significativos da História da Dança}

Quando falamos sobre "momentos significativos", temos que perguntar: por que considerar alguns momentos da história da dança como sendo mais significativos do que outros? Razões para isso podem ser encontradas na particular "canonização" da dança e no fenômeno de "evidência" ao qual me referi anteriormente.

A historiadora de dança finlandesa Johanna Laakkonen forneceu valioso insight sobre a canonização a que vou me referir. ${ }^{11}$

O cânone existente na dança é bastante restrito, concentrando-se em um número limitado de obras e artistas. Ao contrário dos respectivos cânones nas artes visuais, literatura e música, os cânones em dança não foram, na maioria dos casos, abertamente discutidos e analisados.

A canonização dá poder aqueles que criam o cânone, as obras de arte que se considera haverem trazido mudanças importantes na forma da arte; empodera seus criadores (autores, compositores, coreógrafos, etc), e até mesmo aqueles que estão familiarizados com o cânone (aqueles que possuem o conhecimento considerado importante). Este conceito dá suporte à construção de linearidade na historiografia da dança; ele negligencia, e até mesmo exclui, atividades que foram vitais durante um determinado período, mas têm sido consideradas insignificantes em termos de sua influência sobre o desenvolvimento da forma de arte. A dança se preocupa com dois tipos de cânone, o cânone repertorial e o cânone disciplinar. $O$ primeiro significa o conjunto de obras que é regularmente executado e as obras centrais de um determinado período histórico. $\mathrm{O}$ cânone disciplinar engloba vários elementos, tais como convenções de pesquisa, instituições, metodologias, sistemas de crenças, temas para estudo ou linguagem. O cânone disciplinar "dá forma e define uma auto visão da disciplina do que é padrão, aceitável e até mesmo desejável.'12

\footnotetext{
${ }^{10}$ Huddlestone, Performative Memory, p. 7.

${ }^{11}$ Laakkonen, Johanna: Canon and Beyond. Edvard Frazer and the Imperial Russian Ballet, 1908-1910. Helsinki: Academia Scientiarium Fennica 2009, p. 23-28.

${ }^{12}$ Laakkonen, Canon and Beyond, p. 28.
} 
Os cânones repertorial e disciplinar estão estreitamente interligados. Repertórios formam e manipulam pesquisa: as obras que são mais frequentemente realizadas tendem a ser estudadas com frequência. E no sentido contrário, as instituições acadêmicas podem influenciar o que se torna canônico dando visibilidade a obras que não tenham sido previamente acessíveis, assim expondo-as à avaliação e à crítica.

Historiadores da dança, bem como bailarinos interessados em história, têm que lidar com o cânone. Eles podem, no entanto, ampliar seu repertório - não só através de novas descobertas para além do cânone, mas também através de sua conscientização dos encontros fenomenológicos que possam ocorrer no repertório durante as performances experienciadas como eventos.

\section{SEIS - Encontros de Performance e Vestígios, Descontinuidade, Fragmentação}

Recentes historiografias de dança concordam com a definição de que coreografias, enquanto prática organizacional do movimento, são os componentes significativos do repertório. Ao tratar de estrutura, prática e movimento, a definição atual deixa para trás uma entendimento da coreografia como originariamente um ato estético ou fato histórico. No entanto, eu gostaria de sugerir a ligação desta noção "móvel" da coreografia com a noção mais ampla de encontro da performance. É claro, os encontros podem ser experimentados em qualquer performance genuína. Eles estão igualmente refletidos em documentos sobre dança, nos inventários de técnicas de dança e em arquivos de movimento pessoais. Encontros de performance ocorrem como "momentos iniciais de interação explosiva"13 entre o observador/leitor e o performer e/ ou a performance - in actu ou refletida em um documento. Seguindo o entendimento de Huddlestone de fenomenologia, os encontros performativos incluem a contemplação, a observação, bem como a pesquisa que pode ter lugar depois do encontro do indivíduo com o evento de performance. Toda essa reflexão intelectual, no entanto, é propulsionada pela memória do momento experiencial do encontro entre o observador e o evento de performance e retorna para ela.

Eles não separam o espectador/leitor do movimento encontrado in actu ou em um documento. E é - nas palavras de Maurice Merleau-Ponty - esta "persuasão em direção à realidade"14 que potencializa a experiência teatral e também potencializa o

\footnotetext{
${ }^{13}$ Huddlestone, Performative Memory, p. 8.

${ }^{14}$ Merleau-Ponty citado em Huddlestone, Performative Memory, p. 10.
} 
seu resultado, o conhecimento autêntico e fenomenológico de um momento. É também Merleau-Ponty quem aponta a importância da memória:

\begin{abstract}
A fim de preencher a percepção, memórias precisam ter sido habilitadas pelo caráter fisionômico dos dados. Antes de qualquer contribuição pela memória, o que é visto deve, no momento presente, então organizar-se de forma a apresentar-me uma imagem em que eu possa reconhecer minhas experiências anteriores. ${ }^{15}$
\end{abstract}

Uma possibilidade de se deparar com a experiência de uma performance e, consequentemente, de ir além do cânone e do questionamento de repertório é olhar para material de origem histórica como uma seleção ou coleção de vestígios performáticos. Esta pesquisa-criação de traços se baseia no fato/conhecimento fenomenológico de que um corpo produziu o evento performático - ao escrever sobre dança, ao escrever uma trilha musical para uma dança ou desenhando uma posição ou um movimento; isso cria um momento de interação explosiva com a pessoa que está lendo ou visualizando corpo e/ou movimento.

\title{
SETE - Desejo
}

A fim de compreender e experienciar um momento de interação explosiva, é útil observar os conceitos de Roland Barthes de punctum e studium, que ele apresenta em seu livro Camera Lucida (1981) ${ }^{16}$ em relação à fotografia. ${ }^{17} \mathrm{Em}$ contraste com o punctum - isto é, o detalhe autenticamente originário da fotografia - Barthes utiliza o termo studium para descrever o contexto cultural, um contexto que é "em última análise sempre codificado, [enquanto] o punctum não é". Enquanto as fotografias, conforme verificado através do studium, "não emergem, não partem; elas estão anestesiadas e presas, como borboletas", a experiência do punctum, um "campo cego" é apresentado para o exterior.

Palestras/performances, lidando com a "história enquanto prática", baseiam-se nas - inquietantes - experiências de 'campos cegos', fornecendo no entanto "imagens críveis" - nas palavras da teórica da performance Peggy Phelan, imagens que evocam o desejo porque oscilam entre memória, visão e amor. Palestras/performances envolvem pesquisa e análise como uma ressonância contínua da experiência.

\footnotetext{
${ }^{15}$ Merleau-Ponty citado em Huddlestone, Performative Memory, p. 10.

${ }^{16}$ N.T. - Publicado no Brasil com o título "A Câmara Clara". BARTHES, Roland. A Câmara Clara. Nota sobre a fotografia. Rio de Janeiro: Nova Fronteira, 1984.

17 Minha terminologia e linha de argumentação neste parágrafo, assim como as citações de Barthes, Camera Lucida, foram tirados de Huddlestone, Performative Memory, p. 15.
} 
A validação da experiência pela pesquisa e análise não serve como uma defesa baseada em evidências, mas sim como um meio de reforçar a credibilidade. No entanto, esta credibilidade da "história da dança enquanto prática" não é uma aproximação arquivística da história da dança, pelo contrário:

O corpo pode se apropriar das estruturas do movimento, descobre continuidades históricas da mesma forma que também sempre irá experimentar a diferença. Entender, refletir e expor explicitamente essas diferenças como um elemento produtivo da memória histórica da cultura torna a dança $[\ldots]$ apta para a teoria $[\ldots] .{ }^{18}$

Palestras/performances histório-coreográficas são experimentos em colaboração ${ }^{19}$, eles permitem insights na complexa questão da comunicação - em uma pluralidade de níveis tanto sincrônicos quanto diacrônicos e oscilando entre produção e recepção, entre os eventos e artefatos.

\footnotetext{
${ }^{18}$ Hardt, Yvonne: Prozessuale Archive. Wie Tanzgeschichten von Tänzern geschrieben werden. In: Odenthal, Johannes (ed.): Tanz.de. Zeitgenössischer Tanz in Deutschland - Strukturen im Wandel - eine neue Wissenschaft. [arbeitsbuch 2005]. Hamburg: Theater der Zeit 2005, p. 34-41, p. 37.

${ }^{19}$ Bojana Kunst estabeleceu um modelo para a (pós-moderna) colaboração discutindo o "labor" e a "ação" do trabalho dramatúrgico. Ver The Economy of Proximity: Dramaturgical Work in Contemporary Dance, (útima visita em 02/01/2012).
} 